Journal of Telenursing (JOTING)

Volume 2, Nomor 2, Desember 2020

e-ISSN: 2684-8988

p-ISSN: 2684-8996

DOI: https://doi.org/10.31539/joting.v2i2.1631

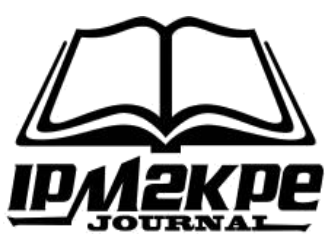

\title{
FAKTOR-FAKTOR YANG BERPENGARUH TERHADAP PERNIKAHAN USIA DINI
}

\author{
Erni Riany ${ }^{1}$, Riska Yanuarti ${ }^{2}$, Bintang Agustina Pratiwi ${ }^{3}$, Wulan Angraini ${ }^{4}$ \\ Universitas Muhammadiyah Bengkulu ${ }^{1,2,3,4}$ \\ Erniriany21@gmail.com ${ }^{1}$
}

\begin{abstract}
ABSTRAK
Penelitian ini bertujuan untuk mengetahui faktor-faktor yang berpengaruh terhadap pernikahan usia dini di Kecamatan Air Rami Kabupaten Mukomuko. Metode penelitian ini adalah penelitian kuantitatif dengan pendekatan cross sectional study. Hasil penelitian menunjukkan faktor yang berpengaruh terhadap pernikahan usia dini di Kecamatan Air Rami Kabupaten Mukomuko antara lain pengetahuan $(\mathrm{p}=0,000)$, sikap $(\mathrm{p}=0,004)$, pendapatan orang tua $(\mathrm{p}=0,001)$, keterpaparan media informasi $(\mathrm{p}=0,901)$, pengaruh teman sebaya $(\mathrm{p}=0,569)$, peran orang tua orang tua $(\mathrm{p}=0,000)$, jumlah anggota keluarga $(\mathrm{p}=0,039)$ sedangkan factor yang tidak berpengaruh terhadap pernikahan usia dini di Kecamatan Air Rami Kabupaten Mukomuko yaitu keterpaparan media informasi $(\mathrm{p}=0,901)$, pengaruh teman sebaya $(\mathrm{p}=0,569)$, dan budaya $(\mathrm{p}=0,104)$. Simpulan, ada pengaruh antara pengetahuan, sikap, pendapatan orang tua, peran orang tua, anggota keluarga terhadap terhadap pernikahan usia dini. Sedangkan yang tidak berpengaruh terhadap pernikahan usia dini adalah keterpaparan media informasi, pengaruh teman sebaya, budaya.
\end{abstract}

Kata Kunci: Pernikahan, Usia Dini

\section{ABSTRACT}

This study aims to determine the factors that influence early marriage in Air Rami District, Mukomuko Regency. This research method is a quantitative study with a crosssectional study approach. The results showed that the factors that influence early marriage in Air Rami District, Mukomuko Regency include knowledge ( $p=0.000)$, attitude $(p=0.004)$, parents' income $(p=0.001)$, exposure to information media $(p=$ $0.901)$, the influence of peers $(p=0.569)$, the role of parents $(p=0.000)$, the number of family members $(p=0.039)$, while the factor that did not affect early marriage in Air Rami District, Mukomuko Regency was exposure to information media ( $p=0.901$ ), peer influence $(p=0.569)$, and culture $(p=0.104)$. In conclusion, there is an influence between knowledge, attitudes, parents' income, parents' role, and family members in early marriage. Meanwhile, what did not affect early marriage was exposure to information media, peer influence, culture.

Keywords: Marriage, Early Age 


\section{PENDAHULUAN}

Hasil Survei Demografi dan Kesehatan Indonesia (SDKI) 2017 menunjukkan bahwa persentase hasil SDKI 2017 hanya berbeda tipis dengan hasil SDKI 2012. Proporsi perempuan yang menikah pada usia 15-19 tahun sebanyak $15 \%$ sedangkan proporsi perempuan usia 20-24 tahun sebanyak 7\%. Hasil statistik kesejahteraan rakyat tahun 2018 yang diadakan oleh BPS, menunjukkan bahwa pernikahan usia dini pada perempuan usia <16 tahun sebanyak 15,66\%, perempuan menikah usia 17-18 tahun sebanyak 20,03\% dan perempuan yang menikah pada usia 19-20 tahun sebanyak $22,96 \%$.

Menurut data Badan Pusat Statistik (2018) menyebutkan Provinsi di Indonesia dengan jumlah persentase pernikahan usia muda tertinggi adalah Provinsi Kalimantan Selatan sebanyak 22,77\%, Provinsi Jawa Barat sebanyak 20,93\% dan Provinsi Jawa Timur sebanyak 20,73\%. Dilihat dari data Badan Pusat Statistik Provinsi Bengkulu data perempuan menikah di usia di bawah 16 tahun untuk provinsi Bengkulu selama tiga tahun terakhir ini setiap tahun selalu ada peningkatan yakni pada tahun 2017 ditemukan dengan presentase $16,17 \%$, pada tahun 2018 ditemukan dengan presentase 16,66\% dan untuk tahun 2019 ditemukan dengan presentase 17,24\%.

Badan Pusat Statistik Provinsi Bengkulu pada tahun 2019 merilis data perempuan yang menikah di usia di bawah 16 tahun dengan persentase tertinggi ditemukan 28,38\% berada di Kabupaten Mukomuko, menyusul Kabupaten Bengkulu Tengah dengan persentase 27,27\%, Kabupaten Kepahiang dengan persentase 21,11\%, Kabupaten Seluma dengan persentase 19,49\%, Kabupaten Rejang Lebong dengan persentase 18,58\%, Kabupaten Lebong dengan persentase 17,30\%, Kabupaten Bengkulu Selatan dengan persentase 16,27\%, Kabupaten kaur dengan persentase 16,07\%, Kabupaten Bengkulu Utara dengan persentase $14,76 \%$, dan Kota Bengkulu dengan persentase 7,16\% (BPS Provinsi Bengkulu, 2019).

Berdasarkan survei awal yang dilakukan peneliti di Badan Kependudukan Dan Keluarga Berencana Nasional (BKKBN) Kabupaten Mukomuko mencatat dari tahun 2015 hingga tahun 2019 pasangan usia subur berdasarkan usia kawin pertama, data untuk istri berusia dibawah 21 tahun sebanyak 23.705 orang dan jumlah pasangan usia subur berdasarkan kelompok umur istri dibawar 20 tahun sebanyak 518 orang.

Dari data tersebut kecamatan Air Rami menjadi salah satu kecamatan yang jumlah pasangan usia subur berdasarkan kelompok umur istri $<20$ tahun terbanyak dari empat tahun terakhir ini yakni berjumlah 81 istri dengan presentase 3,32\%. Pernikahan dini dapat berdampak pada terputusnya sekolah, perekonomian yang rendah, bahaya kehamilan juga kelahiran bayi yang BBLR dan kurangnya asupan gizi yang cukup.

\section{METODE PENELITIAN}

Jenis dan rancangan penelitian yang digunakan adalah penelitian observasional analitik pada metode kuantitatif dengan pendekatan cross sectional study. Populasi dalam penelitian ini adalah seluruh pasangan usia subur berdasarkan umur istri yang sudah menikah pada tahun 2015-2019 di Kecamatan Air Rami Kabuupaten Mukomuko baik yang menikah di usia $<20$ tahun dan usia $>20$ tahun.

Pada penelitian ini teknik pengambilan sampel yang digunakan adalah accidental sampling dengan jumlah sampel 121 responden. Teknik pengumpulan data menggunakan data primer dan sekunder dengan teknik analisa data menggunakan analisis univariate dan bivariate. 


\section{HASIL PENELITIAN}

Analisis Univariat

Tabel. 1

Distribusi Pernikahan Usia Dini

\begin{tabular}{ccccccc}
\hline \multicolumn{7}{c}{ Statistic } \\
\hline Variabel & $\mathrm{N}$ & Mean & Median & Minimum & Maksimum & Std.Deviation \\
\hline $\begin{array}{l}\text { Pernikahan } \\
\text { usia dini }\end{array}$ & 121 & 19,47 & 19,00 & 15 & 29 & 2,778 \\
\hline
\end{tabular}

Berdasarkan tabel 1 didapatkan nilai rata-rata sebanyak 19,47 dan nilai median 19,00 dengan nilai minimum 15 dan nilai maksimum 29 dengan standar deviasi 2,778.

Tabel. 2

Distribusi Pengetahuan

\begin{tabular}{ccccccc}
\hline \multicolumn{7}{c}{ Statistic } \\
\hline Variabel & N & Mean & Median & Minimum & Maksimum & Std.Deviation \\
\hline Pengetahuan & 121 & 6,26 & 6,00 & 1 & 10 & 2,039 \\
\hline
\end{tabular}

Berdasarkan tabel 2 didapatkan total dari variabel pengetahuan dengan nilai ratarata sebanyak 6,26 dan nilai median 6,00 dengan nilai minimum 1 dan nilai maksimum 10 dengan standar deviasi 2,039.

Tabel. 3

Distribusi Sikap

\begin{tabular}{lrccccc}
\hline \multicolumn{7}{c}{ Statistic } \\
\hline Variabel & N & Mean & Median & Minimum & Maksimum & Std.Deviation \\
\hline Sikap & 121 & 32,04 & 32,00 & 23 & 44 & 3,743 \\
\hline
\end{tabular}

Berdasarkan tabel 3 dari hasil penelitian untuk variabel sikap didapatkan nilai rata-rata sebanyak 32,04 dan nilai median 32,00 dengan standar deviasi 3,743.

Tabel. 4

Distribusi Pendapatan Orang Tua

\begin{tabular}{ccccccc}
\hline \multicolumn{7}{c}{ Statistic } \\
\hline Variabel & $\mathrm{N}$ & Mean & Median & Minimum & Maksimum & $\begin{array}{c}\text { Std. } \\
\text { Deviation }\end{array}$ \\
\hline $\begin{array}{l}\text { Pendapatan } \\
\text { Orang Tua }\end{array}$ & 121 & 1.446 .281 & 1.500 .000 & 1.000 .000 & 3.000 .000 & 513572,7 \\
\hline
\end{tabular}

Berdasarkan tabel 4 dari hasil penelitian diketahui variabel pendapatan orang tua responden memiliki nilai rata-rata sebanyak 1.446.281 dan nilai median 1.500,000 dengan standar deviasi 513572,7. 
Tabel. 5

Distribusi Keterpaparan

Media Informasi

\begin{tabular}{lcccccc}
\hline \multicolumn{7}{c}{ Statistic } \\
\hline \multicolumn{1}{c}{ Variabel } & $\mathrm{N}$ & Mean & Median & Minimum & Maksimum & Std.Deviation \\
\hline $\begin{array}{l}\text { Media } \\
\text { Informasi }\end{array}$ & 121 & 1,04 & 1,00 & 0 & 9 & 0,879 \\
\hline
\end{tabular}

Berdasarkan tabel 5 hasil penelitian diketahui total variabel pengaruh media komunikasi memiliki nilai rata-rata sebanyak 1,04 dengan standar deviasi 0,879.

Tabel. 6

Distribusi Pengaruh

Teman Sebaya

\begin{tabular}{ccccccc}
\hline \multicolumn{7}{c}{ Statisties } \\
\hline Variabel & $\mathrm{N}$ & Mean & Median & Minimum & Maksimum & Std.Deviation \\
\hline Teman Sebaya & 121 & 3,12 & 3,00 & 0 & 9 & 2,086 \\
\hline
\end{tabular}

Berdasarkan tabel 6 hasil penelitian diketahui total 121 responden untuk variabel teman sebaya memiliki total nilai rata-rata sebanyak 3,12 dengan standar deviasi 2,086.

Tabel. 7

Distribusi Peran Orang Tua

\begin{tabular}{lcccccc}
\hline \multicolumn{7}{c}{ Statistic } \\
\hline \multicolumn{1}{c}{ Variabel } & $\mathrm{N}$ & Mean & Median & Minimum & Maksimum & Std.Deviation \\
\hline $\begin{array}{l}\text { Peran Orang } \\
\text { Tua }\end{array}$ & 121 & 8,78 & 9,00 & 4 & 10 & 1,452 \\
\hline
\end{tabular}

Berdasarkan tabel 7 hasil penelitian diketahui total 121 responden untuk variabel peran orang tua memiliki total nilai rata-rata sebanyak 8,78 dengan standar deviasi 1,452 .

Tabel. 8

Distribusi Budaya

\begin{tabular}{ccccccc}
\hline \multicolumn{7}{c}{ Statistic } \\
\hline Variabel & $\mathrm{N}$ & Mean & Median & Minimum & Maksimum & Std.Deviation \\
\hline Total & 121 & 0,77 & 1,00 & 0 & 5 & 0,844 \\
\hline
\end{tabular}

Berdasarkan tabel 8 hasil penelitian diketahui total 121 responden untuk variabel Budaya memiliki total nilai rata-rata sebanyak 0,77 dengan standar deviasi 0,844.

Tabel. 9

Distribusi Jumlah Saudara Kandung

\begin{tabular}{ccccccc}
\hline \multicolumn{7}{c}{ Statisties } \\
\hline Variabel & $\mathrm{N}$ & Mean & Median & Minimum & Maksimum & Std.Deviation \\
\hline $\begin{array}{c}\text { Jumlah Saudara } \\
\text { Kandung }\end{array}$ & 121 & 3,14 & 3,00 & 1 & 8 & 1,260 \\
\hline
\end{tabular}


Berdasarkan tabel 9 diketahui bahwa total 121 responden untuk variabel jumlah saudara kandung memiliki total nilai rata-rata sebanyak 3,14 dengan standar deviasi 1,260 .

\section{Analisis Bivariat}

Tabel. 10

Pengaruh Faktor Pengetahuan terhadap Pernikahan Usia Dini

\begin{tabular}{cccc}
\hline \multirow{2}{*}{ Variabel } & \multicolumn{3}{c}{ Pernikahan Usia Dini } \\
\cline { 2 - 4 } & $\mathrm{R}$ & $\mathrm{P}$ Value & $\mathrm{N}$ \\
\hline Pengetahuan & 0,483 & 0,000 & 121 \\
\hline
\end{tabular}

Berdasarkan tabel 10 didapatkan nilai $\mathrm{R}$ hitung $=0,483$ dan nilai $\mathrm{P}=0,000$ sehingga faktor pengetahuan dengan pernikahan usia dini menunjukkan ada pengaruh yang signifikan dan berpola positif artinya perempuan terhadap pengetahuan kurang baik maka semakin beresiko melakukan pernikahan usia dini.

Tabel. 11

Pengaruh Faktor Sikap terhadap Pernikahan Usia Dini

\begin{tabular}{cccc}
\hline \multirow{2}{*}{ Variabel } & \multicolumn{3}{c}{ Pernikahan Usia Dini } \\
\cline { 2 - 4 } & $\mathrm{R}$ & $\mathrm{P}$ Value & $\mathrm{N}$ \\
\hline Sikap & 0,257 & 0,004 & 121 \\
\hline
\end{tabular}

Berdasarkan tabel 11 didapatkan nilai $\mathrm{R}$ hitung $=0,257$ dan nilai $\mathrm{P}=0.004$. sehingga faktor sikap terhadap pernikahan usia dini menunjukkan menunjukkan ada pengaruh yang signifikan dan berpola positif artinya perempuan terhadap sikap kurang baik maka semakin beresiko melakukan pernikahan usia dini.

Tabel. 12

Pengaruh Faktor Pendapatan Orang Tua terhadap Pernikahan Usia Dini

\begin{tabular}{cccc}
\hline \multirow{2}{*}{ Variabel } & \multicolumn{3}{c}{ Pernikahan Usia Dini } \\
\cline { 2 - 4 } & $\mathrm{R}$ & $\mathrm{P}$ Value & $\mathrm{N}$ \\
\hline Pendapatan Orang Tua & 0,311 & 0,001 & 121 \\
\hline
\end{tabular}

Berdasarkan tabel 12 didapatkan nilai $\mathrm{R}$ hitung $=0,311$ dan nilai $\mathrm{P}=0,001$ sehingga faktor pendapatan orang tua terhadap pernikahan usia dini menunjukkan ada pengaruh yang signifikan dan berpola positif artinya semakin pendapatan orang tua orang tua rendah semakin beresiko melakukan pernikahan usia dini.

Tabel. 13

Pengaruh Faktor Keterpaparan Media Informasi terhadap Pernikahan Usia Dini

\begin{tabular}{cccc}
\hline Variabel & \multicolumn{3}{c}{ Pernikahan Usia Dini } \\
\cline { 2 - 4 } & $\mathrm{R}$ & $\mathrm{P}$ Value & $\mathrm{N}$ \\
\hline $\begin{array}{c}\text { Keterpaparan } \\
\text { media Informasi }\end{array}$ & $-0,011$ & 0,901 & 121 \\
\hline
\end{tabular}


Berdasarkan tabel 13 didapatkan nilai $\mathrm{R}$ hitung $=-0,011$ dan nilai $\mathrm{P}=0,901$ sehingga faktor keterpaparan media informasi terhadap pernikahan usia dini menunjukkan tidak ada pengaruh yang signifikan dan berpola negatif artinya semakin tinggi keterpaparan media informasi maka semakin tidak beresiko terjadinya pernikahan usia dini.

Tabel. 14

Pengaruh Faktor Pengaruh Teman Sebaya terhadap Pernikahan Usia dini

\begin{tabular}{cccc}
\hline \multirow{2}{*}{ Variabel } & \multicolumn{3}{c}{ Pernikahan Usia Dini } \\
\cline { 2 - 4 } & $\mathrm{R}$ & $\mathrm{P}$ Value & $\mathrm{N}$ \\
\hline Pengaruh teman sebaya & 0,052 & 0,569 & 121 \\
\hline
\end{tabular}

Berdasarkan tabel 14 didapatkan nilai $\mathrm{R}$ hitung $=0,052$ dan nilai $\mathrm{P}=0,569$ sehingga faktor pengaruh teman sebaya terhadap pernikahan usia dini menunjukkan tidak ada pengaruh yang signifikan dan berpola positif artinya semakin besar pengaruh teman sebaya maka semakin beresiko terjadinya pernikahan usia dini.

Tabel. 15

Pengaruh Faktor Peran Orang Tua terhadap Pernikahan Usia dini

\begin{tabular}{cccc}
\hline \multirow{2}{*}{ Variabel } & \multicolumn{3}{c}{ Pernikahan Usia Dini } \\
\cline { 2 - 4 } & $\mathrm{R}$ & $\mathrm{P}$ Value & $\mathrm{N}$ \\
\hline Peran orang tua & 0,346 & 0,000 & 121 \\
\hline
\end{tabular}

Berdasarkan tabel 15 didapatkan nilai $\mathrm{R}$ hitung $=0,346$ dan nilai $\mathrm{P}=0,000$ sehingga maka faktor peran orang tua terhadap pernikahan usia dini menunjukkan ada pengaruh yang kuat dan berpola positif artinya semakin besar peran orang tua maka semakin beresiko melakukan pernikahan usia dini.

Tabel. 16

Pengaruh Faktor Budaya terhadap

Pernikahan Usia dini

\begin{tabular}{cccc}
\hline \multirow{2}{*}{ Variabel } & \multicolumn{3}{c}{ Pernikahan Usia Dini } \\
\cline { 2 - 4 } & $\mathrm{R}$ & $\mathrm{P}$ Value & $\mathrm{N}$ \\
\hline Budaya & $-0,149$ & 0,104 & 121 \\
\hline
\end{tabular}

Berdasarkan tabel 16 didapatkan nilai $\mathrm{R}$ hitung $=-0,149$ dan nilai $\mathrm{P}=0,104$ sehingga faktor budaya terhadap pernikahan usia dini menunjukkan tidak ada pengaruh yang signifikan dan berpola negatif artinya semakin besar pengaruh budaya maka semakin tidak beresiko terjadinya pernikahan usia dini.

Tabel. 17

Pengaruh Faktor Jumlah Anggota Keluarga terhadap Pernikahan Usia Dini

\begin{tabular}{cccc}
\hline \multirow{2}{*}{ Variabel } & \multicolumn{3}{c}{ Pernikahan Usia Dini } \\
\cline { 2 - 4 } & $\mathrm{R}$ & $\mathrm{P}$ Value & $\mathrm{N}$ \\
\hline Jumlah Anggota Keluarga & $-0,188$ & 0,039 & 121 \\
\hline
\end{tabular}


Berdasarkan tabel 17 didapatkan nilai $\mathrm{R}$ hitung $=-0,188$ dan nilai $\mathrm{P}=0,039$ sehingga faktor jumlah anggota keluarga terhadap pernikahan usia dini menunjukkan ada pengaruh yang signifikan dan berpola negative artinya semakin banyak jumlah anggota keluarga maka akan semakin tidak beresiko terjadinya pernikahan usia dini.

\section{PEMBAHASAN}

\section{Pengetahuan}

Berdasarkan hasil penelitian didapatkan, ada pengaruh yang signifikan antara faktor pengaruh terhadap pernikahan usia dini di Kecamatan Air Rami Kabupaten Mukomuko dengan nilai $\mathrm{r}=0,483$ dan nilai $p=0.000$. Hal ini menunjukkan bahwa semakin baik pengetahuan seseorang maka semakin kecil kemungkinan seorang wanita melakukan pernikahan usia dini dan sebaliknya semakin rendah pengetahuan seseorang maka semakin besar kemunginan seorang perempuan melakukan pernikahan usia dini. Hal ini dapat dilihat dari jawaban responden saat pengisian kuesioner yang menunjukkan bahwa dari 121 responden terdapat 57 responden yang dapat menjawab pertanyaan dengan jawaban benar di atas median 6,00 sehingga dikatakan memiliki pengetahuan baik.

Hasil dari penelitian yang dilakukan oleh Yulivia (2018) menunjukan $\mathrm{p}$ value $=$ 0,042 artinya ada pengaruh yang segnifikan antara rata-rata pengetahuan PUS yang berpengetahuan baik dan berpengetahuan kurang baik terhadap pernikahan usia dini. Sejalan dengan penelitian yang dilakukan oleh Angraini (2019) yang berjudul faktor yang mempengaruhi pernikahan usia dini didapatkan hasil $\mathrm{P}$ value $=0,000$ artinya ada pengaruh faktor pengetahuan terhadap terjadinya pernikahan usia dini sama halnya dengan penelitian yang dilakukan oleh Mawarni (2019) didapatkan hasil bahwa ada hubungan yang signifikan antara pengetahuan dan pernikahan usia dini dengan $\mathrm{p}$ value $=0,001(<0,05)$.

\section{Sikap}

Berdasarkan hasil penelitian didapatkan ada pengaruh yang signifikan antara faktor Sikap terhadap pernikahan usia dini di Kecamatan Air Rami Kabupaten Mukomuko dengan nilai $\mathrm{R}$ hitung $=0,257$ dan nilai $\mathrm{P}=0,004$. Hal ini menunjukkan bahwa semakin baik sikap seseorang maka semakin kecil kemungkinan seorang wanita melakukan pernikahan usia dini dan sebaliknya semakin rendah sikap seseorang maka semakin besar kemunginan seorang perempuan melakukan pernikahan usi dini. Hal ini dapat dilihat dari jawaban responden saat pengisian kuesioner yang menunjukkan bahwa dari 121 responden terdapat 63 responden yang dapat menjawab pertanyaan dengan jawaban benar diatas median 32,00 sehingga dikatakan memiliki sikap baik.

Menurut penelitian yang dilakukan Pratiwi (2019) didapatkan hasil bahwa ada hubungan antara sikap dengan pernikahan usia dini di Kabupaten Bengkulu tengah karena perempuan yang memiliki sikap yang negatif tentang pernikahan usia dini tidak mengetahui dampak yang akan ditimbulkan jika melakukan pernikahan usia dini seperti masih kurangnya persiapan dari masing-masing pasangan untuk menghadapi permasalahan ekonomi, tanggung jawab serta kematangan dari fikis, psikis maupun sosial. Sejalan dengan Penelitian yang dilakukan oleh Samsi (2020) mendapatkan hasil statistik dari uji chi-square dengan $\mathrm{p}$ value $=0,000$ artinya ada hubungan yang signifikan antara sikap dengan kejadian pernikahan usia dini pada remaja. 


\section{Pendapatan Orang Tua}

Berdasarkan hasil penelitian didapatkan ada pengaruh yang signifikan antara faktor pendapatan orang tua terhadap pernikahan usia dini di Kecamatan Air Rami Kabupaten Mukomuko dengan nilai $\mathrm{R}$ hitung $=0,311$ dan nilai $\mathrm{P}=0,001$. Hal ini menunjukkan bahwa pendapatan orang tua akan mempengaruhi seorang perempuan melakukan pernikahan usia dini karena dapat dilihat dari jawaban responden saat pengisian kuesioner yang menunjukkan orang tua seseorang yang menikah usia dini ada $38,0 \%$ yang memiliki pendapatan perbulan Rp. 1.000 .000 dan pendapatan yang paling besar yakni Rp 3.000.000 dengan persentase 4,1\% dengan ini menunjukkan kategori besar ataupun kecil pendapatan orang tua seseorang hampir sama sehingga berpengaruh dengan keputusan untuk melakukan pernikahan usia dini.

Hasil penelitian dilakukan oleh Halawani (2017) didapatkan bahwa status ekonomi dengan pernikahan usia dini pada remaja putri dengan nilai $\mathrm{P}$ value $=0,003$ $(<0,05)$ serta nilai $0 \mathrm{R}=3,28$ artinya remaja putri yang status ekonomi rendah mempunyai resiko 3,28 kali menikah dini di banding remaja yang status ekonomi tinggi. Sejalan dengan penelitian dengan Mawarni (2019) didapatkan hasil $\mathrm{p}$ value = $0,001(\mathrm{p}<0,05)$ artinya ada pengaruh yang signifikan antara penghasilan orang tua dengan pernikahan usia dini.

\section{Keterpaparan Media Informasi}

Berdasarkan hasil penelitian didapatkan tidak ada pengaruh yang signifikan antara faktor keterpaparan media informasi dengan pernikahan usia dini di Kecamatan Air Rami Kabupaten Mukomuko dengan nilai $\mathrm{R}$ Hitung $=-0,011$ dan $\mathrm{P}=0,901$. Dengan ini menunjukkan bahwa terpapar ataupun kurang terpaparnya responden dengan media informasi tidak akan mempengaruhi seorang peempuan untuk melakukan pernikahan usia dini. Karena dapat dilihat dari jawaban responden saat pengisian kuesioner penelitian yang menunjukan bahwa jawaban responden yang kurang terpapar atau yang terpapar media informasi hampir sama sehingga tidak ada berpengaruh dengan keputusan untuk melakukan pernikahan usia dini.

Namun penelitian dari Yulivia (2018) menunjukan bahwa hasil uji stasistik menunjukan nilai $\mathrm{P}$ value $=0,310$ artinya tidak ada pengaruh yang signifikan antara keterpaparan media dengan terjadinya pernikahan usia dini. Tidak sejalan dengan penelitian yang dilakukan oleh Pratiwi (2019) didapatkan hasil bahwa penggunaan handphone justru dapat memperlancar komunikasi dan pertemuan informan dengan pasangan atau orang yang baru dikenal melalui media sosial, sehingga saat pertemuan bisa mengarah ke perbuatan yang tidak baik.

\section{Pengaruh Teman Sebaya}

Berdasarkan hasil penelitian didapatkan tidak ada berpengaruh yang signifikan antara faktor pengaruh teman sebaya terhadap pernikahan usia dini di Kecamatan Air Rami Kabupaten Mukomuko dengan nilai $\mathrm{R}$ hitung $=0,052$ dan nilai $\mathrm{P}=0,569$. Hal ini menunjukan bahwa tidak adanya pengaruh atau adanya pengaruh dari teman sebaya seseorang tidak akan mempengaruhi seorang perempuan untuk melakukan pernikahan usia dini karena dilihat dari jawaban responden saat pengisian kuesioner yang menunjukkan pengaruh teman sebaya dengan kategori berpengaruh atau tidak berpengaruh hampir sama sehingga tidak berpengaruh dengan keputusan melalukan pernikahan usia dini. 
Menurut penelitan yang di lakukan oleh Pratiwi (2019) didapatkan hasil $\mathrm{P}=0,378$ artinya teman sebaya tidak ada berpengaruh terhadap keputusan menikah seseorang. Hal tersebut dikarenakan keputusan menikah adalah pilihan individu bukan atas dasar pengaruh teman sebaya yang sudah menikah namun atas dasar pilihan individu yang beranggapan bila sudah menikah maka akan berkurang beban orang tua dan orang tua akan merasa bahagia.

\section{Peran Orang Tua}

Berdasarkan hasil penelitian didapatkan ada pengaruh yang signifikan antara faktor peran oang tua terhadap pernikahan usia dini di Kecamatan Air Rami Kabupaten Mukomuko dengan nilai $\mathrm{R}$ hitung $=0,346$ dan nilai $\mathrm{P}=0,000$. Hal ini dapat dilihat dari jawaban responden saat pengisian kuesioner yang mengatakan bahwa sebagian besar orang tua meluangkan waktu untuk mendiskusikan tentang permasalahan yang dihadap namun tidak semua dari orang tua responden memberikan nasehat tentang menikah usia dini dan orang tua tidak melarang untuk menikah jika belum tamat SMA. Penelitian Galih (2018) didapatkan hasil uji statistik p value $=0,000(<0,05)$ artinya ada hubungan yang signifikan antara peran orang tua dengan pernikahan usia dini.

\section{Budaya}

Berdasarkan hasil penelitian didapatkan tidak ada pengaruh yang signifikan antara faktor Budaya terhadap pernikahan usia dini di Kecamatan Air rami Kabupaten Mukomuko dengan nilai $\mathrm{R}$ hitung $=-0,149$ dan nilai $\mathrm{P}=0,104$. Hal ini menunjukkan bahwa ada atau tidak ada pengaruh budaya yang ada di lingkungan tempat tingal seseorang maka tidak akan mempengaruhi seseorang perempuan untuk melakukan pernikahan usia dini. Dapat dilihat dari jawaban responden saat pengisian kuesioner menunjukan bahwa faktor budaya yang berpengaruh atau tidak berpengaruh hampir sama sehingga tidak berpengaruh dengan keputusan melakukan pernikahan usia dini.

Namun menurut penelitian yang dilakukan Halawani (2017) didapatkan hasil bahwa bila remaja putri yang percaya dengan budaya akan mempunyai resiko 3,939 kali untuk menikah usia dini dibandingkan dengan remaja putri yang tidak percaya dengan budaya. Penelitian sejalan dengan penelitian Yulivia (2018) yang menunjukan bahwa hasil dari uji statistik didapatkan tidak ada pengaruh yang signifikan mengenai rata-rata budaya PUS pada pernikahan usia dini yang tidak berpengaruh dan yang berpengaruh.

\section{Jumlah Anggota Keluarga}

Berdasarkan hasil penelitian di dapatkan ada pengaruh yang signifikan antara jumlah anggota kelurga terhadap pernikahan usia dini di Kecamatan Air Rami Kabupaten Mukomuko dengan nilai $\mathrm{R}$ hitung $=-0,188$ dan nilai $\mathrm{P}=0.039$. Hal ini dapat dilihat dari jawaban responden saat pengisian kuesioner yang mengatakan bahwa jumlah anggota keluarga banyak dan sedikit mempengaruhi seorang perempuan dalam mengambil keputusan untuk menikah usia dini.

Penelitian yang dilakukan oleh Stang \& Mambaya (2011) didapatkan hasil nilai $\mathrm{p}=0,019$ dan karena nilai $\mathrm{p}<0,05$ artinya ada hubungan antara jumlah saudara dengan pernikahan usia dini. Dapat disimpulkan bahwa semakin banyak jumlah anggota keluarga maka semakin besar pula kemungkinan orang tua akan menikahkan anaknya diusia dini dengan asumsi bahwa kan meringankan beban ekonomi keluarga. 


\section{SIMPULAN}

Hasil analisis uji korelasi didapatkan hasil yang berpengaruh terhadap pernikahan usia dini adalah pengetahuan, sikap, pendapatan orang tua, peran orang tua, jumlah anggota keluarga. Sedangkan yang tidak berpengaruh terhadap pernikahan usia dini adalah keterpaparan media informasi, pengaruh teman sebaya dan budaya.

\section{SARAN}

Diharapkan untuk menjalin kerjasama dengan BKKBN dan lembaga kesehatan yang lain untuk memberikan informasi beserta edukasi kepada remaja khususnya putri dan orang tua tentang pendewasaan usia pernikahan (PUP) dan dampak kesehatan maupun social dari pernikahan usia dini.

\section{DAFTAR PUSTAKA}

Angraini, W., Pratiwi, B. A., Febriawati, H., Yanuarti, R., Anita, B., \& Oktarianita, O. (2019). Faktor yang Mempengaruhi Terjadinya Pernikahan Usia Dini. Jurnal Biometrika dan Kependudukan, $\quad 8(2), \quad 183-191$. http://dx.doi.org/10.20473/jbk.v8i2.2019.183-191

BKKBN Prov Bengkulu. (2019). Pus Berdasarkan Usia Kawin Pertama. Diakses dari http://pk.bkkbn.go.id/PK/Laporan/Default.aspx

BPS. (2018). Statistik Kesejahteraan Rakyat Provinsi Bengkulu, Bengkulu

BPS. (2019). Statistik Kesejahteraan Rakyat Provinsi Bengkulu, Bengkulu

Galih, D.W. (2018). Hubungan Peran Orang Tua dengan Persepsi Remaja tentang Pernikahan Usia Dini di Sma N 1 Banguntapan Bantul. Skripsi. Fakultas Ilmu Kesehatan Universitas 'Aisyiyah Yogyakarta

Halawani, P. N. (2017). Faktor yang Berhubungan dengan Pernikahan Usia Dini terhadap Remaja Putri. Jurnal Endurance, 2(3). https://ejournal.kopertis10.or.id/index.php/endurance/article/download/2283/835

Mawarni, M. (2019). Hubungan Pengetahuan, Budaya, Lingkungan Tempat Tinggal dan Sosial Ekonomi dengan Pernikahan Dini pada Wanita. Jurnal Fakultas Kesehatan Masyarakat, 13(1), 11-15

Pratiwi, B., Angraini, W., Padila, P., Nopiawati, N., \& Yandrizal, Y. (2019). Analisis Pernikahan Usia Dini di Kabupaten Bengkulu Tengah Tahun 2017. Jurnal Kesmas Asclepius, 1(1),

14-24. https://doi.org/https://doi.org/10.31539/jka.v1i1.575

Samsi, N. (2020). Faktor yang Mempengaruhi Kejadian Pernikahan Usia Dini pada Remaja Putri Dikecamatan Lembah Melintang. Jurnal Kesehatan Global, 3(2), 55-61

Stang, S., \& Mambaya, E. (2011). Faktor yang Berhubungan dengan Pernikahan Dini Dikelurahan Pangli Kecamatan Sesean Kabupaten Toraja Utara. Media Kesehatan Masyarakat Indonesia Universitas Hasanuddin, 7(1), 105-110

Yulivina, E. Dewi, \& F. Avianty, I. (2018). Faktor-Faktor yang Mempengaruhi Pernikahan Dini pada Pus (Pasangan Usia Subur) di Kelurahan Pasir Jaya Kecamatan Bogor Barat Kota Bogor Tahun 2018. Promotor: Jurnal Mahasiswa Kesehatan Masyarakat, 1(1), 53-61. http://ejournal.uikabogor.ac.id/index.php/PROMOTOR/article/view/1428 